Brit. F. vener. Dis. (1973) 49, 151

\title{
Contrasting views on the infectivity of gonorrhoea
}

\author{
W. F. FELTON \\ St. Thomas's Hospital, London
}

There is no generally accepted view of the infectivity of gonorrhoea. Many venereologists believe that it is highly infectious, but there is also a body of opinion that considers it less so.

It is fundamental to the understanding of the epidemiology of an infectious disease to know how infectious it is. The purpose of this paper is to make a case in favour of high infectivity and to point out the need for further study.

A well known reference which favours a high level of infectivity is taken from a paper by Marcussen (1953).

'Exact statements on the possibility of transmission or on the time required for one case to multiply into ten are not available, but Alexander, Schoch, and Mantooth estimated the risk of transmitting syphilis (dark-field positive cases) as from 59.9 to 62.3 per cent. An investigation carried out in Copenhagen confirmed these results. It was observed that $60 \cdot 0$ to $66 \cdot 3$ per cent. of persons in sexual contact with patients suffering from contagious syphilis developed or had developed the disease. The corresponding figures for gonorrhoea were 84.9 to $87 \cdot 8$ per cent.'.

More recently Holmes, Johnson, and Trostle (1970) published a report, of which the summary ran as follows:

'Among the crew of an aircraft carrier visiting the Philippines for 6 days, 2,191 men admitted sexual contact with a group of females known to have a prevalence of 19.7 per cent. of $N$. gonorrhoeae infection. The mean number of consorts visited by each man was 1.2. 77 per cent. of the men did not use prophylaxis. 88 cases of gonorrhoea were actually observed among the males in the shipboard population following the liberty period. With this information a risk estimate was developed and it appears that the risk of acquiring gonorrhoea by contact with an infected female was 22 per cent.'.

It is argued that, if infectivity had been 100 per cent., 399 infections would have been expected. In fact, 88 cases (22 per cent.) were observed. The method of reasoning is sound. The control of the male population is exemplary (Holmes, Johnson, and Floyd, 1967). The results of the investigation of the female population are, however, open to serious criticism, and render the 'risk estimate' a frail support for an estimate of the infectivity of gonorrhoea.

(1) It was not established that the sample of females contacted by the sailors could properly be compared with that selected by the investigators.

The sailors selected a maximum of 2,629 girls. The number could have been less if there was any duplication during the 6 days in March and April, 1966. It was assumed that the girls were chosen wholly from the 4,800 licensed hostesses who operated from 170 bars and 47 restaurants. There appears to have been plenty of opportunity of time and place in making a selection.

The investigators selected their sample of females one year later in February, 1967 (Johnson, Holmes, Kvale, Halverson, and Hirsch, 1969). In Olongapo there is a legal requirement for licensed hostesses to be examined weekly. During the week when the investigation started, 2,150 hostesses presented themselves for examination, but the remaining 2,650 stayed away. In the public clinic the investigators chose every third girl standing in the line waiting for her examination, making a total of 702 for the sample.

The difficulties of selecting a good sample are clearly very great, but it is suggested that, in the circumstances, a sampling error affecting the 'risk estimate' by a factor of two would not be surprising.

(2) The second criticism concerns the known prevalence' of 19.7 per cent. of infections with gonorrhoea among the female population. This 'known' figure is only an estimate. It is further submitted that it was not a good estimate.

It was obtained by repeatedly testing females by plating endocervical swabs on Thayer-Martin medium at weekly intervals for 4 weeks. Of the original 702 girls, only 66 completed all five examinations (Table I, overleaf).

The percentages of positive findings over five examinations were added together and it was concluded that this total represented the point prevalence in the sample at the time of the first examination. 
During the 4 weeks the females of the sample were at complete liberty to follow their profession and, whatever the acquisition rate of gonorrhoea may have been in Olongapo at the time, it applied to them.

Johnson and others (1969) justified their conclusion by pointing out that fewer and fewer positives were found each week and that at the fifth examination no new positive cases were found at all. However, the number of 66 who underwent the fifth examination is too small to exclude a chance nil finding. If a further series of examinations had been possible, this would have helped to ascertain how fast new infections were being acquired.

An alternative interpretation of the data is that the risk to the males of acquiring gonorrhoea from these infected females was 32.6 per cent., subject to a suitable factor for sampling error which might be as high as two. The point prevalence is estimated at 13.3 per cent. and the rate of re-infection at 2.7 per cent. per week.
74.7 per cent. for females) were or had been infected. Thin, Williams, and Nicol (1970) examined a group of 157 females all of whom had had recent contact with men suffering from gonorrhoea; the number found infected was $144(91 \cdot 1$ per cent.).

This updating suggests that it is not unreasonable to apply Marcussen's probability of transmission to a Table shown in the A.S.H.A. Joint Statement (1971) entitled 'Sex Contacts named by Type of Exposure' (Table II). The fact that more than half the infections were transmitted at a single exposure suggests a high rate of infectivity. However, the probability of any infection resulting from a single or multiple exposure is a function of the independent variables:

(i) The probability of the exposure being single.

(ii) The probability of the transmission of disease by an infected person.

Applying the laws of probability ${ }^{\star}$, the following equation can be derived:

$=\frac{\text { Probability of single exposure }}{\text { Probability of multiple exposure }} \times \frac{\text { Probability of transmission }}{\text { Probability of no transmission }}$

* (i) If the probabilities of Events $E_{1}$ and $E_{2}$ are $P_{1}$ and $P_{2}$ respectively, then, by definition Event $E_{1}$ is $P_{1} / P_{2}$ as probable as Event $E_{2}$

(ii) The probability of the happening of a multiple event on any given trial is equal to the product of the separate probabilities of its separate constituent events.

The number of single and multiple exposures are known from the ASHA Joint Statement (Table II). per cent. of contacts ( 88.5 per cent. for males and

TABLE I Distribution of infections in the random group by number of times examined and cumulative percentage infected (From Holmes and others, 1969)

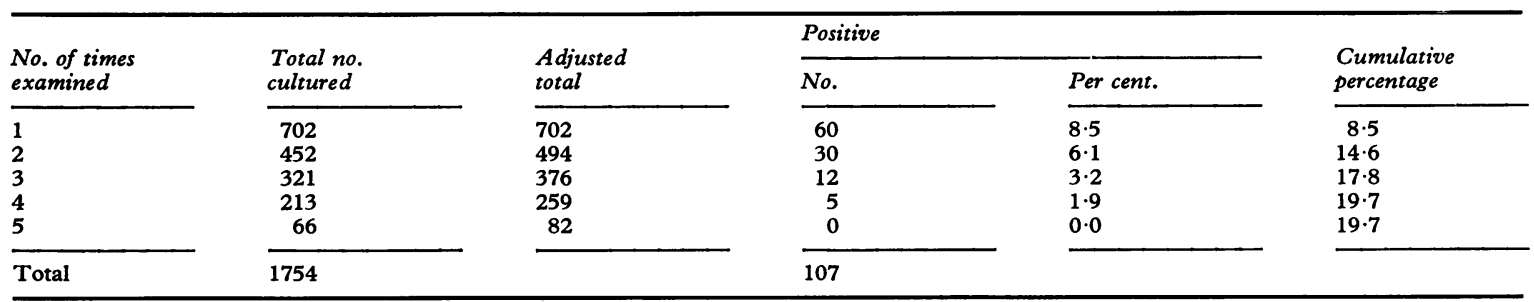

TABLE II Sex contacts of gonorrhoea cases by type of exposure $(A S H A, 1971)$

\begin{tabular}{|c|c|c|c|c|}
\hline Type of exposure & \multicolumn{2}{|c|}{2 States } & \multicolumn{2}{|c|}{25 Cities } \\
\hline $\begin{array}{l}\text { Single exposure opposite sex } \\
\text { Multiple exposure opposite sex } \\
\text { Single exposure same sex } \\
\text { Multiple exposure same sex } \\
\text { Marital partner }\end{array}$ & $\begin{array}{r}39 \\
43 \\
0 \\
0 \\
25\end{array}$ & $\begin{array}{l}36 \cdot 4 \\
40 \cdot 2 \\
- \\
-23 \cdot 4\end{array}$ & $\begin{array}{r}2,138 \\
1,474 \\
84 \\
181 \\
703\end{array}$ & $\begin{array}{r}46 \cdot 7 \\
32 \cdot 2 \\
1 \cdot 8 \\
4 \cdot 0 \\
15 \cdot 3\end{array}$ \\
\hline Total & 185 & & 4,927 & \\
\hline
\end{tabular}


The proportions are calculated from the total of States and Cities and confined to non-marital exposures to the opposite sex. There is no evidence as to the probability of a single exposure, which is given the value of $x$. The two values, Marcussen 0.86 and Holmes and others 0.22 , for the probability of the transmission of gonorrhoea can be tested.

Table III shows that, at the Marcussen probability of transmission, the probability in the sexual pattern of the population that an exposure would be single and isolated is 19 per cent. This is a value which might be considered to agree with clinical experience.

TABLE II I Calculation of the probability of a single exposure using data from Table II and the probability of the transmission of gonorrhoea suggested by Marcussen (1953)

\begin{tabular}{|c|c|}
\hline Proportions of gonorrhoea infections & \\
\hline $\begin{array}{l}\text { Single exposure } \\
\text { Multiple exposure }\end{array}$ & $\begin{array}{l}0.59 \\
0.41\end{array}$ \\
\hline \multicolumn{2}{|l|}{ Probabilities } \\
\hline $\begin{array}{l}\text { Single exposure } \\
\text { Multiple exposure } \\
\text { Transmission (Marcussen) } \\
\text { No transmission (Marcussen) }\end{array}$ & $\begin{array}{l}x \\
1-x \\
0 \cdot 86 \\
0 \cdot 14\end{array}$ \\
\hline \multicolumn{2}{|l|}{ then } \\
\hline $\begin{aligned} \frac{0.59}{0.41} & -\frac{x}{1-x} \times \frac{0.86}{0.14} \\
x & =0.19\end{aligned}$ & \\
\hline
\end{tabular}

Table IV shows that, at the level of infectivity reported by Holmes, Johnson, and Trostle (1970), the probability of any exposure in the sexual pattern being single and isolated would be 84 per cent. Clinical experience suggests that casual encounters are not so frequent.

A method of checking the value of the probability of an exposure being single is to make the assumption that individuals infected with gonorrhoea are drawn from the same population as those infected with primary and secondary syphilis. If this were true, taking the syphilis data from the ASHA Joint
TABLE IV Calculation of probability of a single exposure using data from Table II and the probability of the transmission of gonorrhoea suggested by Holmes and others (1970)

\begin{tabular}{|c|c|}
\hline Proportions of gonorrhoea infections & \\
\hline $\begin{array}{l}\text { Single exposure } \\
\text { Multiple exposure }\end{array}$ & $\begin{array}{l}0.59 \\
0.41\end{array}$ \\
\hline \multicolumn{2}{|l|}{ Probabilities } \\
\hline $\begin{array}{l}\text { Single exposure } \\
\text { Multiple exposure } \\
\text { Transmission (Holmes and others) } \\
\text { No transmission (Holmes and others) }\end{array}$ & $\begin{array}{l}x \\
1-x \\
0 \cdot 22 \\
0 \cdot 78\end{array}$ \\
\hline \multicolumn{2}{|l|}{ then } \\
\hline$\frac{0.59}{0.41}:=\frac{x}{1-x} \times \frac{0.22}{0.78}$ & \\
\hline
\end{tabular}

Statement (Table V), the equation used for gonorrhoea would be applicable. The value of the probability of a single exposure ought to be the same for both syphilis and gonorrhoea.

Table VI shows that, using the syphilis data from the Joint Statement (Table V) for the total of States

TABLE VI Calculation of probability of a single exposure using data from Table $V$ and the probability of the transmission of primary and secondary syphilis suggested by Marcussen (1953)

\begin{tabular}{lll}
\hline Proportions of primary and secondary syphilitic infections & \\
${$\cline { 1 - 1 }$} }$ & $\begin{array}{l}0.26 \\
\text { Multiple exposure }\end{array}$ & \\
\hline Probabilities & \\
\hline Single exposure & $x$ \\
Multiple exposure & $1-x$ \\
Transmission & 0.63 \\
No transmission & 0.37 \\
\hline & \\
then & \\
$\frac{0 \cdot 26}{0.74}=\frac{x}{1-x} \times \frac{0.63}{0.37}$ & \\
$x=0.17$ &
\end{tabular}

TABLE V Sex contacts of primary and secondary cases of syphilis by type of exposure $(A S H A, 1971)$

\begin{tabular}{|c|c|c|c|c|}
\hline Type of exposure & \multicolumn{2}{|c|}{34 States } & \multicolumn{2}{|c|}{102 Cities } \\
\hline $\begin{array}{l}\text { Single exposure opposite sex } \\
\text { Multiple exposure opposite sex } \\
\text { Single exposure same sex } \\
\text { Multiple exposure same sex } \\
\text { Marital partner }\end{array}$ & $\begin{array}{r}2,894 \\
8,609 \\
806 \\
1,357 \\
1,468\end{array}$ & $\begin{array}{r}19 \cdot 1 \\
56 \cdot 9 \\
5 \cdot 3 \\
9 \cdot 0 \\
9 \cdot 7\end{array}$ & $\begin{array}{l}2,190 \\
5,630 \\
1,125 \\
1,857 \\
1,465\end{array}$ & $\begin{array}{r}17 \cdot 9 \\
45 \cdot 9 \\
9 \cdot 2 \\
15 \cdot 1 \\
11 \cdot 9\end{array}$ \\
\hline Total & 15,343 & & 12,342 & \\
\hline
\end{tabular}


and Cities confined to non-marital exposures to the opposite sex, the probability of a single exposure at 17 per cent. is very close to the gonorrhoea calculation at 19 per cent.

\section{Conclusion}

It has been shown that the results of the study of Holmes and others (1970) can be questioned and further work is required to establish the infectivity of gonorrhoea. The results of the probability studies are interesting but, standing on their own, are neither weighty nor conclusive.

An important point is that, if a control programme is based on infectivity at the 20 per cent. level when the actual level is 80 per cent., that programme may achieve only a quarter of its predicted result.
I should like to thank Dr. C. S. Nicol for his help and encouragement in preparing this paper.

\section{References}

American Social Health Association (1971) (Joint Statement) 'Today's V.D. Control Problem'

Holmes, K. K., Johnson, D. W., and Floyd, T. M. (1967) f. Amer. med. Ass., 202, 461

,-- and Trostle, H. J. (1970) Amer. F. Epidemiol., 91, 170

Johnson, D. W., Holmes, K. K., Kvale, P. A., Halverson, C. W., and Hirsch, W. P. (1969) Ibid., 90, 438

Marcussen, P. V. (1953) Amer. F. Syph., 37, 355

Pedersen, A. H. B., and Harrah, W. D. (1970) Publ. Hlth Rep. (Wash.), 85, 997

Thin, R. N. T., Williams, I. A., Nicol, C. S. (1970) Brit. F. vener. Dis., 47, 27 